\title{
The Effect of Pumice Rate on the Gamma Absorption Parameters of Concrete
}

\author{
I. Akkurt ${ }^{a}$, H. Akyildirim ${ }^{a}$, B. Mavi ${ }^{b}$, Ş. KillinçArslan ${ }^{c}$ And C. BaşYiĞitit \\ ${ }^{a}$ Faculty of Arts and Sciences, Department of Physics, Süleyman Demirel University, Isparta, Turkey \\ ${ }^{b}$ Faculty of Arts and Sciences, Department of Physics, Amasya University, Amasya, Turkey \\ ${ }^{c}$ Faculty of Technical Education, Department of Structural Education, Süleyman Demirel University \\ Isparta, Turkey
}

\begin{abstract}
Since the technology concerning gamma radiation showed a rapid development, it became a necessity to be protected from it. One of the common shielding materials for this purpose is concrete. This study aims to give the effect of pumice rate on the gamma radiation attenuation coefficients of normal concrete $\left(\rho=2.476 \mathrm{~g} \mathrm{~cm}{ }^{-3}\right)$ containing different rates of pumice mineral. Pumice, for which the Gölcük region in Isparta province is rich, is a volcanic originated spongy and porous mineral. Although it is a light material, it has a high comprehensive strength and heat resistance. So it became a common construction material in buildings. In the study, the variation of attenuation coefficients for concretes of different pumice rates were measured for 662, 1173 and $1332 \mathrm{keV}$ photons using a $\mathrm{NaI}(\mathrm{Tl})$ detector. The experimental values were compared with the theoretical ones obtained by XCOM code.
\end{abstract}

PACS: $14.70 . \mathrm{Bh}, 25.20 . \mathrm{Dc}$

\section{Introduction}

As the usage of $\gamma$-rays increased in various fields from medical applications to food industry, it became important to get protection from their detrimental effects. There are three general rules of protection: time, distance, and shielding. In most cases, shielding is the main rule to be performed [1]. Although materials such as lead [2], iron are effective $\gamma$-ray shields, mechanical and economical considerations limit their usage to some special areas. Concrete, the main construction material, became an essential $\gamma$-ray shield because it costs relatively low and its physical and mechanical properties such as density, durability, strength and heat resistance can be adjusted by means of adding various minerals [3]. In addition to the mentioned parameters, $\gamma$-ray attenuation coefficient became an important parameter for concrete research. The ability of absorbing $\gamma$-rays of a material is presented by total linear attenuation coefficient $\left(\mu, \mathrm{cm}^{-1}\right)$ which is defined as the interaction probability of a photon at a particular energy, with the medium per unit path length $[1,4]$. A photon mainly interacts with the atoms of the medium by photoelectric, scattering (Compton + Rayleigh) and pair production interactions. So, $\mu$ is the sum of partial linear attenuation coefficients of each interaction. The magnitude of $\mu$ depends on the density and the atomic number of the material and the energy of the incoming $\gamma$-ray $[5,6]$. The attenuation law works exponentially as follows, where $I, I_{0}$ and $x$ are, respectively, the intensities of attenuated, unattenuated photon beams and the thickness of the shield

$$
I=I_{0} \mathrm{e}^{-\mu x} \text {. }
$$

In this study, attenuation properties of concretes including different rates of pumice were investigated both experimentally and theoretically. Pumice, a light, spongy and porous mineral forms after volcanic activities. Though its low density, it is commonly used in buildings as light block and isolation element. The main motivation for this study is that the Gölcük region in Isparta province $\left(30^{\circ} 20^{\prime}-31^{\circ} 33^{\prime}\right.$ East longitudes and $37^{\circ} 18^{\prime}-$ $38^{\circ} 30^{\prime}$ North latitudes) has pumice reserves [7]. One can find similar works on attenuation properties of different types of concretes, which were produced with local minerals, in the literature $[2,6,8-10]$.

\section{Materials and methods}

Three different types of concretes, namely N, NP, and $\mathrm{P}$ with pumice rates of $0 \%, 50 \%$, and $100 \%$, respectively, were produced. The pumice was obtained from Gölcük region and the Portland cement type 42.5 from Göltaş Plant in Isparta. The water/cement ratio was 0.5 for all concrete samples.

The chemical compositions of concretes and cement are as in Table. Attenuation experiments were held by using a gamma spectrometer system consisting of a $3^{\prime \prime} \times 3^{\prime \prime}$ Canberra mark $\mathrm{NaI}(\mathrm{Tl})$ scintillator and a $16 \mathrm{k}$ multi channel analyzer that communicates with PC via Genie2000 software. A detailed description of the setup and calibration can be found elsewhere $[3,6] .{ }^{137} \mathrm{Cs}(662 \mathrm{keV})$ and ${ }^{60} \mathrm{Co}$ 
(1173 and $1332 \mathrm{keV}$ ) radioactive sources were used in the experiments. Attenuation coefficients were determined by graphical method, in which the slope of the fitted line to the plot of radiation transmission rate given by $\ln \left(I_{0} / I\right)$ versus sample thickness $x$ gives the total linear attenuation coefficient. For this purpose, $5 \times 5 \times 2 \mathrm{~cm}^{3} \mathrm{di}-$ mensioned slabs were prepared. The maximum errors in the measurements were obtained by the below formula. The errors at $I$ and $I_{0}$ were copied from the spectrum software

$$
\Delta \mu=\sqrt{\left(\frac{\Delta I}{I}\right)^{2}+\left(\frac{\Delta I_{0}}{I_{0}}\right)^{2}+\left(\frac{\Delta x}{x}\right)^{2} \ln \left(\frac{I_{0}}{I}\right)^{2}} .
$$

For comparison, attenuation coefficients of lead $(\rho=$ $\left.11.3 \mathrm{~g} / \mathrm{cm}^{3}\right)$, the standard $\gamma$-ray shielding material, were used [2]. On the other hand, XCOM code [11], a web based code to calculate the mass attenuation coefficients [4] of elements, compounds or mixtures such as concretes at $10^{-3}-10^{5} \mathrm{MeV}$ photon energy range, was used for theoretical calculations. For calculation work, the chemical composition data of concretes were given as input to the code and mass attenuation coefficients were outputs at stated energy range. Then the $\mu$ values were obtained by multiplying mass attenuation coefficients by concrete densities.

The chemical compositions of concretes and Portland cement.

TABLE

\begin{tabular}{c|c|c|c|c}
\hline \hline Compound & $\mathrm{N}\left(2.48 \mathrm{~g} / \mathrm{cm}^{3}\right)$ & $\mathrm{NP}\left(1.83 \mathrm{~g} / \mathrm{cm}^{3}\right)$ & $\mathrm{P}\left(1.57 \mathrm{~g} / \mathrm{cm}^{3}\right)$ & $\mathrm{PC} 42.5$ \\
\hline $\mathrm{CaO}$ & 0.3939 & 0.2507 & 0.1212 & 0.6100 \\
$\mathrm{MgO}$ & 0.1097 & 0.0617 & 0.0106 & 0.0356 \\
$\mathrm{NaO}$ & 0.0039 & 0.0022 & 0.0396 & 0.0000 \\
$\mathrm{Na}_{2} \mathrm{O}$ & 0.0000 & 0.0000 & 0.0362 & 0.0000 \\
$\mathrm{~K}_{2} \mathrm{O}$ & 0.0005 & 0.0004 & 0.0080 & 0.0011 \\
$\mathrm{Fe}_{2} \mathrm{O}_{3}$ & 0.0046 & 0.0055 & 0.0000 & 0.0381 \\
$\mathrm{P}_{2} \mathrm{O}_{5}$ & 0.0000 & 0.0001 & 0.0000 & 0.0000 \\
$\mathrm{CO}_{2}$ & 0.3146 & 0.1640 & 0.5601 & 0.0000 \\
$\mathrm{SiO}_{2}$ & 0.1270 & 0.0945 & 0.0935 & 0.2256 \\
$\mathrm{H}_{2} \mathrm{O}$ & 0.0742 & 0.0869 & 0.1210 & 0.0000 \\
$\mathrm{Al}_{2} \mathrm{O}_{3}$ & 0.0104 & 0.0155 & 0.0058 & 0.0711 \\
$\mathrm{SO}_{2}$ & 0.0046 & 0.0054 & 0.0000 & 0.0270 \\
$\mathrm{BaSO}_{4}$ & 0.0000 & 0.3082 & 0.0000 & 0.0000 \\
$\mathrm{MgCO}_{3}$ & 0.0000 & 0.0003 & 0.0000 & 0.0000 \\
$\mathrm{NaCl}_{\mathrm{CaCO}}$ & 0.0000 & 0.0003 & 0.0000 & 0.0000 \\
$\mathrm{MnO}_{2}$ & 0.0000 & 0.0067 & 0.0000 & 0.0000 \\
$\mathrm{NiO}$ & 0.0000 & 0.0007 & 0.0000 & 0.0000 \\
& 0.0000 & 0.0007 & 0.0000 & 0.0000
\end{tabular}

\section{Results and discussion}

The total linear attenuation coefficients of three different types of concretes each containing different rate of pumice mineral were measured for three photon energies. The maximum error in the experimental results found to be only $5 \%$. The experimental results were compared with theoretical ones calculated by using XCOM code. Also, concretes were compared with lead. Figure 1 shows this comparison from which a good agreement between theoretical and experimental results can be seen. It is clear from this figure that coefficients of lead are the highest and coefficients of $\mathrm{P}$ concrete are the lowest on the whole energy region. A remarkable point in Fig. 1 is that the dependence of linear attenuation coefficient on $\gamma$ energy occurs in different ways. This is because different interaction mechanisms are dominant at different energy regions $[1,2,10]$. From Fig. 1, at $0.2-2 \mathrm{MeV}$ region, approximately, where the experimental energy values are in, while the linear attenuation coefficients are the highest for $\mathrm{N}$ concrete, they are the lowest for $\mathrm{P}$ concrete.

Figure 2 shows the variation of linear attenuation coefficients with density of the shielding materials for both experimental and theoretical values. As seen, the coefficients of three $\gamma$ energies are linearly proportional to density of the material. Finally, Fig. 3 presents the result that this study aimed to show. According to the figure, 


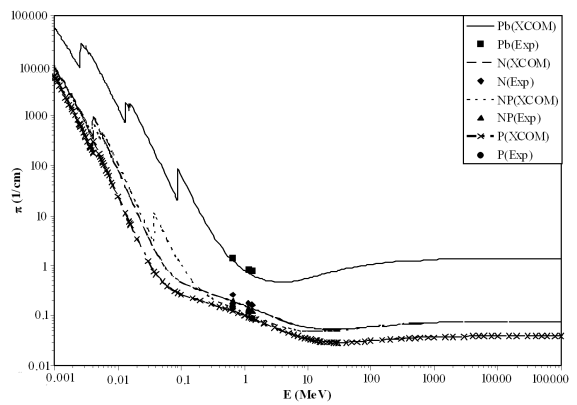

Fig. 1. The calculated and measured values of linear attenuation coefficients.

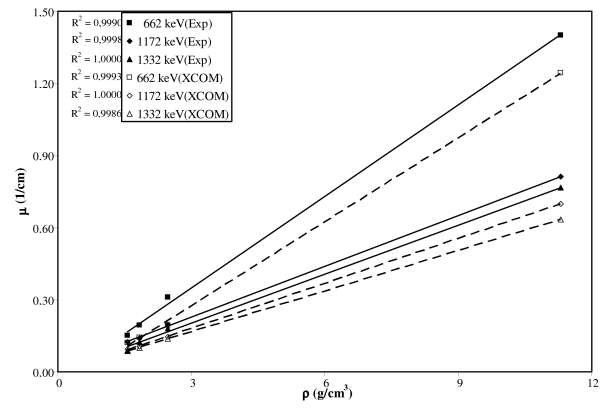

Fig. 2. Variation of linear attenuation coefficients with density of the tested materials. Solid lines and dashed lines correspond to linear fits of experimental and theoretical values, respectively.

increasing pumice rate decreases the value of attenuation coefficients. This could be strongly due to the increase in porosity and decrease in density of the concrete following the addition of pumice mineral.

\section{Acknowledgments}

The authors wish to thank to TUBITAK (Türkiye Bilimsel ve Teknik Araştırma Kurumu) for partly supporting this work under project number 106M127.

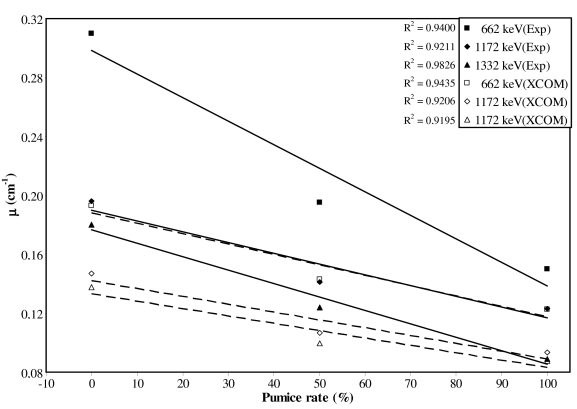

Fig. 3. Variation of linear attenuation coefficients with pumice rate. Solid lines and dashed lines correspond to linear fits of experimental and theoretical values, respectively.

\section{References}

[1] G. Eaves, Principles of Radiation Protection, Iliffe Books Ltd, London 1964.

[2] I. Akkurt, H. Akyıldırım, B. Mavi, S. Kılınçarslan, C. Başyiğit, Ann. Nucl. Energy 37, 910 (2010).

[3] S. Kilincarslan, I. Akkurt, C. Basyigit, Mater. Sci. Eng. A 424, 83 (2006).

[4] J.H. Hubbell, Report NSRDS-NBS 29, National Bureau of Standards, Washington DC 1969.

[5] T. Jaeger, Principles of Radiation Protection Engineering, McGraw-Hill Book Co., New York 1965.

[6] I. Akkurt, H. Akyıldırım, B. Mavi, S. Kılınçarslan, C. Başyiğit, Radiat. Measurem. 45, 827 (2010).

[7] O. Cengiz, E. Sener, F. Yagmurlu, J. Asian Earth Sci. 27, 155 (2006).

[8] I. Akkurt, S. Kilincarslan, C. Basyigit, B. Mavi, H. Akyildirim, Int. J. Phys. Sci. 4, 588 (2009).

[9] I. Akkurt, C. Basyigit, S. Kilincarslan, B. Mavi, Prog. Nucl. Energy 46, 1 (2005).

[10] I.I. Bashter, Ann. Nucl. Energy 24, 1389 (1997).

[11] M.J. Berger, J.H. Hubbell, NBSIR 87-3597: Photon Cross-Sections on a Personal Computer. National Institute of Standards, Gaithersburg, http://physics.nist.gov/PhysRefData/Xcom/ Text/XCOM.html MD 20899 USA (1987). 